physiology of anæsthesia may be made more clear, as the matters therein handled are not so luminously treated as are other portions of the book. In "Notes" such as these it is natural to find some matters left out which should have been included, nor could the authors be expected within so narrow a compass to compress so wide a subject as that with which they have essayed to deal. It is, however, a pity that they have rot explained more clearly and succinctly the way in which nitrous oxide produces anæsthesia, and so emphasised its extreme safety in dental and minor operations. Less important matters receive a larger share of attention. The useful little book still needs some revision. The dual alliance of Mr. Underwood-who writes as a surgeon and as a dentist-with Mr. Braine-who speaks as an expert-has undoubtedly resulted in producing a serviceable manual for dental students.

Nature's Hygiene. By C. T. KINGZETT, F.I.C., F.C.S., Past Vice-President, Society of Pablic Analysts, \&c. London : Baillière, Tindall, and Cox. Fourth edition. 1894.

Is preparing a fourth edition of this work, besides a careful revision of the last edition, the author has added chapters on Phagocytosis and Immunity, and on Alimentation and Foods, and has embodied in the text the results of his further investigations of the chemistry of the aerial oxidation of turpentines and other essential oils. It is claimed for this volume that it has "gradually grown from a series of scientific essays into a systematic treatise on hygiene." We take it that most authors, in putting forward a "systematic treatise on hygiene," would have had something to say on the methods and appliances in use for ventilation; on the means of removal of excreta and refase matters from a house; on lighting and warming; on the distribation and storage of water; on clothing, and such-like matters-but on all these topics the writer is silent. Mr. Kingzett writes as a chemist and has handled his subject mainly from a chemical standpoint; he, therefore, is principally concerned with important chemical processes which are constantly going on in nature-e.g., oxidation, nitrification, fermentation, putrefaction, the life-history of micro-organisms and the influence of these on the preservation of health, and the incidence of disease. On all these matters Mr. Kingzett is thoroughly at home and writes exhaustively and fully. In speaking of typhus fever, however, the author states that this fever may result when the poison finds a home in the intestines. Again, an experiment of Lister is quoted in which it is demonstrated that coagulation of blood does not occur outside the body if care be taken, while collecting it, to exclude the presence of the micro-organisms which are contained in ordinary air. In discussing micro-organisms Mr. Kingzett is, of course, an ardent advocate of the view that their injurious effects are due to the chemical products which they elaborate during their growth in the body, and he is convinced that no further material advancement of knowledge in bacteriology can take place until the chemistry of the subject has been thoroughly explored.

The author describes pus as "a fluid containing a common degraded form of bioplasm or germinal matter, which goes on living and reproducing itself, but which cannot form tissue," and he considers that every kind of bioplasm may by similar degradation give rise to it. We are also told that pus may result from a mucous membrane, from an excessive supply of nutriment to it. For the purpose of disinfecting a room by fumigation Mr. Kingzett recommends either the evaporation of Sanitas oil or the burning of sulphur candles. The concluding chapters of the volume are devoted to a consideration of the essential oils and their atmospheric oxidation in nature, the laboratory, and the factory, in the course of which the method of manufacturing the various Sanitas preparations, of which Mr. Kingzett was the inventor, is described.

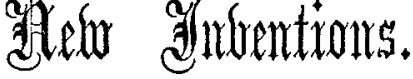

NEW SPLINTS FOR USE IN FRACTURES OF THE LONG BONES OF THE LOWER EXTREMITY, EMBODYING THE PRINCIPLE OF THE EVERTED FOOTPIECE.

THE two splints I am describing have been constructed by me in association with Mr. Arbuthnot Lane. One of them, of which I give an illustration, is a modification of the "long Liston," and is used for fracture of the femur, while the other is suited to fractures of the tibia and fibula and to erosions and excisions of the knee and ankle-joints. Both have been designed with a view to carry out Mr. Lane's views as to the fallacy of the vertical footpiece.

With oblique fractures of both tibia and fibula, when it was apparent that by splinting alone perfect results could not be attained, Mr. Lane has cut down on the site of fracture and united the bones with screws, using subsequently the following splint, consisting of a leg-piece, interruptions, and foot-piece. The leg-piece is a trough of tin with punched-out perforations, and is padded with wool or, preferably, with elephant plaster. It extends upwards to the gluteal fold and below to within about 5 in. from the sole. The measurement refers to an adult. It is better to perforate the tin trough so as to enable padding to be more securely applied and to give a firm hold to the bandages. The interruptions stand out 2 in. on either side of the splint, to allow of the passage of a roller bandage between limb and bar. At the heel the two interruption bars are joined in such a way that the perforation made in the centre of the joining bar is $2 \frac{1}{2}$ in. above the bottom of the tin trough. The wooden footpiece is attached to the joining bar on a pivot, secured by a stout screw, which passes through the footpiece $2 \frac{1}{2} \mathrm{in}$. from the posterior edge of the heel. Thus the footpiece, fitting the foot well, has its posterior edge on the same level as the padded trough of the splint, while it rotates right and left about an axis passing along the length of the whole splint $2 \frac{1}{2}$ in. above the surface of the trough of the splint. The reason for this will be apparent, for, experimentally, I find that, for lateral rotation through $50^{\circ}$ in a trough of this kind, the axis in an adult of moderate stature and development is situated $2 \frac{3}{8}$ in. from the posterior edge of the heel, and is $\frac{1}{8}$ in. external to the centre of the line joining the two malleoli.

The points to be observed in applying this splint are as follows:1. Mould and pad the trough to fit the leg. 2. Estimate the ordinary rotation outwards of the sound leg in easy supine posture, and adjust the angle of the footpiece to this estimate Rotate the whole injured limb outwards in the splint till it occupies this position. 3. Fasten the foot firmly by a domet bandage to the footpiece, the bandage being passed beneath the interruptions, and so arranged as not to allow the heel to slip back. Then bandage the leg firmly to the trough. The splint thus arranged gives physiological rest, since the limb is fixed in a position of rotation outwards to the extent which is normal to that individual when lying at rest in the supine position. The angle of this rotation differs somewhat. It is less in the working than in the middle classes, varying inversely with the severity of the 
labour in which the individual is engaged. The advantages claimed for the splint are as follows: Physiological rest of the limb is attained; each section of the limb is fixed and trouble from pressure is completely avoided; the splint is convenient for wounds, compound fractures, and operations ; the same splint may be used for either limb ; the apparatus is comparatively inexpensive.

The modified "long Liston" splint (vide illustration), for ase in cases of fracture and injury of the femur, where rest of the hip-joint is required, consists of an upper and a back splint. The back splint is of similar make to the one described except that the tin trough is enlarged to surround a greater circumference of the femur. To the upper part of this trough the hip-joint splint is attached by a thumbscrew. It is so arranged that the same splint may be adjusted to either limb. The upper, or hip splint, consists of tronghed sheetiron, $4 \frac{1}{2}$ in. to $5 \mathrm{in}$. in width, with interruptions of $10 \mathrm{in.}$ arranged to avoid pressure at the hip. The upper part of the splint reaches into the axilla and is attached to the body by two bands passing round the chest. The lower section overlaps the tin trough of the back splint, and is attached by the thumbscrew mentioned above. The over-riding of these sections, to the extent of 5 in., allows the same splint to be ased in individuals of considerable difference in stature and build. The splint after bandaging is very rigid, is comfortable to the patient, and is second only to a "Hodgen" for ease in marsing.

Guy's Hospital.

\section{A PALPEBRAL ELEVATOR.}

THE accompanying engravings serve to illustrate a simple instrument for raising the upper lid, which I have found very convenient. It is merely a thin metallic stem, or handle, with longitudinal corrugations. The terminal half-inch or so is applied to the skin of the lid parallel to, and at a little

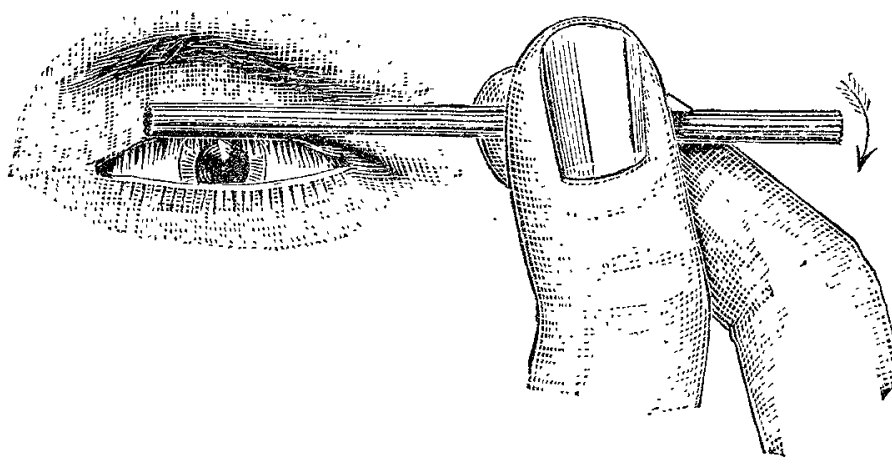

distance from, the ciliary border ; it is then thrust up under the margin of the orbit and at the same time rotated between the finger and thamb in the direction indicated by the arrow, so carrying the eyelid with it. It is not intended for eversion, nor will it conveniently overcome orbicularis spasm, but in all ordinary cases, and more especially in

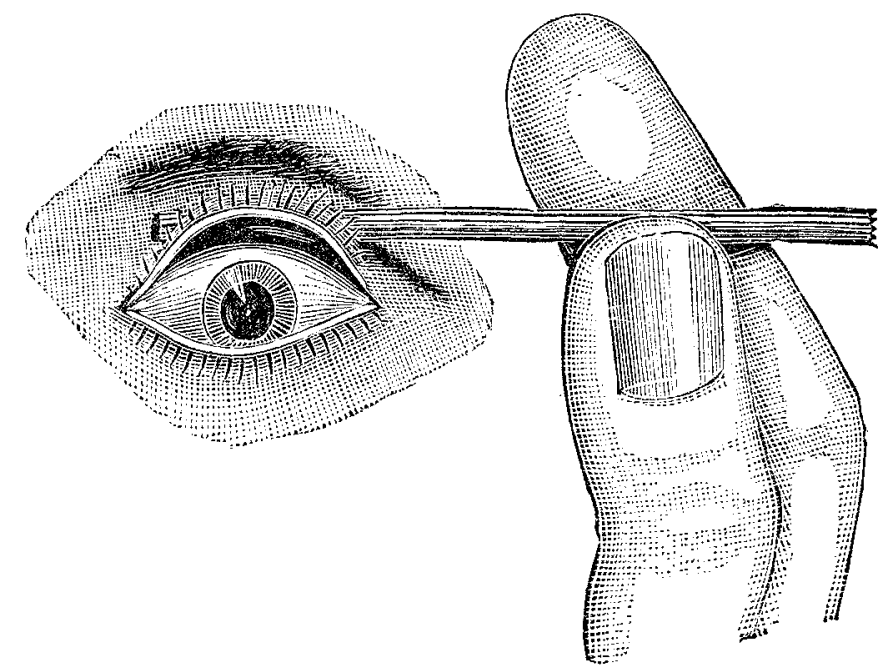

patients with sunken globes and thin flaccid lids, or when the skin is wet with discharge or smeared with ointment, it is of much convenience and utility. Messrs. Arnold and Sons, of West Smithfield, have made some for me, and supply them at a nominal price.

The Charterbouse.

Frederick Bass.

THE NIBESTOS FILTER.

Is this filter a novel feature consists in the employment of an asbestos film similar in form and size to the paper filters commonly used in the laboratory. The adrantage of such an arrangement is, we think, of an important kind, since the undesirable changes taking place in an accumulated deposit, and its contaminating effects upon the water, may be easily avoided by simply replacing the fouled film with a fresh one. The "nibestos" film, which is an asbestos composition, exhibits very marked filtering powers according to our own practical observations, whilst it admits of regulating to any ordinary degree of pressure, so preventing impurities being forced through or the speed of the filter being retarded. It effects a remarkable improvement in the colour of water when viewed in depths, the foreign brownish colour being eliminated, the blue, natural colour of water only remaining. It is an ingenious and effectual device. The filters we recently inspected were exhibited at Halberstadtmansions, 126, Charing-cross-road.

\section{A NEW TROCAR AND CANNULA FOR EMPYEMA.}

IN cases of empyema, where, after the use of the ordinary trocar and cannula, it may be necessary to enlarge the opening for the introduction of the drainage-tube, a little difficulty sometimes occurs. To obviate this I have devised a trocar

$$
\text { W }
$$

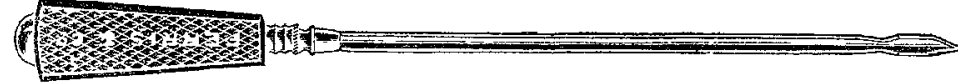

and cannula, with a groove running down one side of the cannula, and a corresponding one on the trocar, so that the opening can easily be enlarged without the risk of the knife slipping. I think the instrument may be used in numerous other instances. The principle might be adapted to the aspirator. The instrument depicted was made for me by Messrs. Ferris and Co. of Bristol.

Flaxton, York. $\quad A L F R E D$ KEBBELL, M.R.C.S. Eng.

\section{A MODIFICATION OF VOLKMANN'S SPOON.}

IN operating on the spinal column for Pott's disease, as in many other cases of necrosis of bone, Volkmann's spoons are of inestimable value, particularly where the bone has died chiefly by molecular disintegration, leaving only small sequestra and débris to be dealt with; but in working at the bodies of the vertebra I have found the usefulness of the spoon impaired and restricted by reason of the depth of the carions bone and the straightness of the instrument in its usual form. I have therefore devised and had constructed spoons the terminal two inches of which are set at an angle of $45^{\circ}$ with their handles. They are made in two forms, in one of which the cutting edge and concavity of the spoon are directed inwards towards the concavity of the elbow thus

FIG. 1.

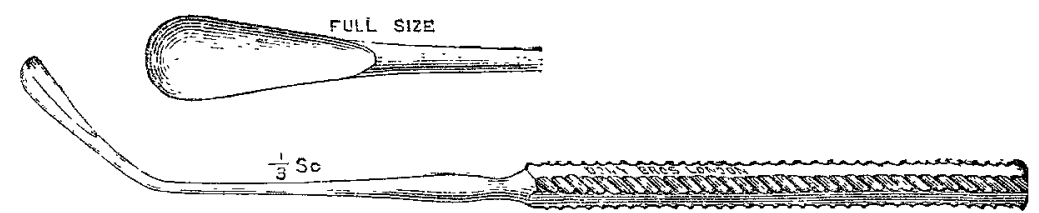

formed, and the other ontwards towards its convexity. The result is two instruments of considerable power, which enable

FrG. 2.

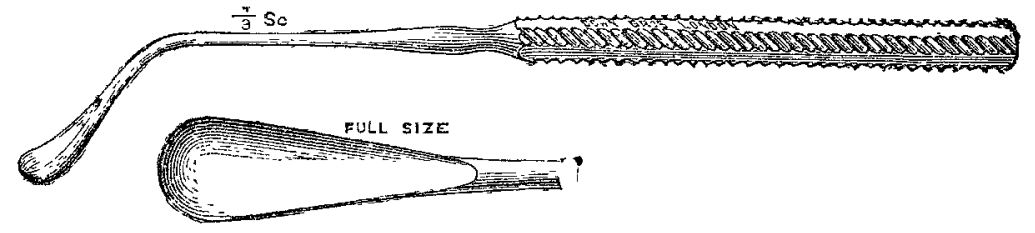

the operator to scrape either towards or away from himself, so that by their means the whole of an ulcerated cavity can be thoroughly gone over irrespectively of its situation in the vertebral body. The handles are strong and serrated, giving a good grip, and the instruments are made in two sizes, as in the case of the ordinary straight spoons. I am indebted to Messrs. Down for the faithful manner in which they have carried out my idea, and I believe that in these instruments surgeons will find a valuable aid in deep and difficult operations.

Friar-street, Reading. Surgeon to the Royal Berkshire Hospital. 